\title{
A Compact Dual-Band CPW-Fed Planar Monopole Antenna for 2.62-2.73 GHz Frequency Band, WiMAX and WLAN Applications
}

\author{
Ahmed Zakaria Manouare ${ }^{1}$, Saida Ibnyaich ${ }^{2}$, Abdelaziz EL Idrissi ${ }^{1}$, Abdelilah Ghammaz $^{1}$ \\ ${ }^{I}$ Department of Applied Physics, Laboratory of Electrical Systems and Telecommunications, Faculty of Sciences \\ and Technologies, Cadi Ayyad University, Marrakesh, Morocco. \\ ${ }^{2}$ Department of Physics, Laboratory of Electronics and Instrumentation, Faculty of Sciences Semlalia, Cadi \\ Ayyad University, Marrakesh, Morocco. \\ ahmedzakaria.manouare@gmail.com \\ Naima Amar Touhami ${ }^{3}$ \\ ${ }^{3}$ Laboratory of Information Systems and Telecommunications, Faculty of Sciences, Abdelmalek Essaadi \\ University, Tetouan, Morocco.
}

\begin{abstract}
In this paper, we present a compact and low-profile monopole antenna with a simple structure for the $2.6-2.73 \mathrm{GHz}$ frequency band, the Worldwide Interoperability for Microwave Access (WiMAX) and the Wireless Local Area Network (WLAN) applications. The first configuration of our antenna mainly consists by three radiating elements: inverted L-shaped Stub1, L-shaped Stub2 and a rectangle Stub3. By adjusting the lengths of the three Stubs, three resonant frequencies can be achieved and adjusted separately. Then, the assembled between Stub2 and Stub3 gives the final design of our proposed antenna with a small overall size of 20 $\mathrm{mm} \times 37 \mathrm{~mm} \times 1.56 \mathrm{~mm}$. From the experimental results it is observed that, the antenna prototype has achieved two operating bandwidths $\left(S_{11} \leq-10 \mathrm{~dB}\right)$ : the first band from 2.62 to $2.73 \mathrm{GHz}(110$ $\mathrm{MHz})$ and a second broadband from 3.02 to $7.30 \mathrm{GHz}(4280 \mathrm{MHz})$ which combines WiMAX and WLAN applications. The antenna also exhibits an almost omnidirectional radiation patterns over the operating bands. The parameters which affect the performance of the antenna in terms of its frequency domain characteristics are studied in this paper. The details of the monopole antenna design along with simulated and experimental results are presented and discussed.
\end{abstract}

Index Terms - CPW-feed, Dual-band antenna, Monopole antenna, Multiband antenna, WiMAX/WLAN applications.

\section{INTRODUCTION}

In modern wireless communication systems, multiband antenna has been playing a very important role for wireless service requirements. Wireless Local Area Network (WLAN) and Worldwide Interoperability for Microwave Access (WiMAX) have been widely applied to mobile devices such as handheld computers and smart phones, more and more engineers and researchers have focused their interests on how to design multiband antennas that can be integrated in a portable wireless communication device for several communication standards. In order to satisfy the IEEE 802.11 
WLAN standards in the $5.2 \mathrm{GHz}(5150-5350 \mathrm{MHz}) / 5.8 \mathrm{GHz}(5725-5825 \mathrm{MHz})$ operating bands and WiMAX 2.6/3.5/5.5 GHz (2500-2690/3400-3690/5250-5850 MHz) bands, multi-band antennas with low cost, compact size, easy fabrication and higher performance are required. Several dual-band antennas for WLAN applications were presented [1-5]. To enhance the bandwidth, a dual wideband monopole antenna was realized with a parasitic patch using electromagnetic coupling mechanism to cover the whole WLAN bands and WiMAX bands. However, the overall size of the antenna is somewhat large $\left(48 \times 58 \mathrm{~mm}^{2}\right)$, occupying much of the device space [6]. A compact wideband LIshaped monopole antenna with enough bandwidth to cover the whole WLAN and WiMAX operating bands was obtained in [7]. A compact dual-wideband antenna with assembled monopoles is proposed in [8]. A coplanar waveguide (CPW)-fed printed monopole antenna with an n-shaped slot for dualband operation is presented in [9]. In [10], a dual-band slotted patch antenna with defective ground has been designed to cover WLAN and WiMAX applications. In reference [11], a CPW-fed compact meandered patch antenna for dual-band operation is presented. In [12], a CPW-fed dual-frequency monopole antenna has been reported. In [13], a square-slot antenna with symmetrical L-strips is presented for WLAN and WiMAX applications, but the three resonant frequencies cannot be tuned independently. Many promising UWB antennas have been discussed in the literature [14-18].

In this paper, we present a compact dual-band CPW-fed planar monopole antenna for $2.6-2.73 \mathrm{GHz}$ frequency band, WiMAX and WLAN applications. The first stage of our design is a simple antenna with three Stubs (Stub1, Stub2 and Stub3) which provides three resonant frequencies at $2.603 \mathrm{GHz}$, $3.429 \mathrm{GHz}$ and $4.584 \mathrm{GHz}$. These frequencies can be tuned individually according to the parameters $\mathrm{L}_{1}, \mathrm{~L}_{2}$ and $\mathrm{L}_{3}$, as shown in Fig. 1 (a). In the second stage, by assembling the Stub2 and the Stub3, as shown in Fig. 1 (b), the proposed antenna satisfies a part of the $2.6 \mathrm{GHz}$ band (first band) from 2.62 to $2.73 \mathrm{GHz}$ and a second wide band from 3.02 to $7.30 \mathrm{GHz}$ is formed to cover all the $5.2 / 5.8 \mathrm{GHz}$ WLAN operating bands and the $3.5 / 5.5 \mathrm{GHz}$ WiMAX operating bands. Details of the antenna design and the effects of the key structure parameters on the antenna performances are neatly examined and discussed.

\section{ANTENNA DESIGN}

The geometries of the initial and proposed CPW-fed monopole antennas are shown in Fig. 1. Both the antennas are designed on a $1.56 \mathrm{~mm}$ thick FR4 substrate having relative permittivity of 4.3 , a loss tangent of 0.025 and having overall dimensions of $20(\mathrm{~W}) \times 37(\mathrm{~L}) \mathrm{mm}^{2}$ and a coppering thickness of the radiator $\mathrm{t}=0.035 \mathrm{~mm}$. The electromagnetic simulation software CST Microwave Studio based on Finite Integration Technique (FIT) is used for the design. In both antennas, the CPW has a feed width of $\mathrm{W}_{\mathrm{f}}=2.8 \mathrm{~mm}$ and a gap distance of $\mathrm{g}=0.4 \mathrm{~mm}$ between the feed and the coplanar ground plane, which corresponds to $50 \Omega$ characteristic impedance. 


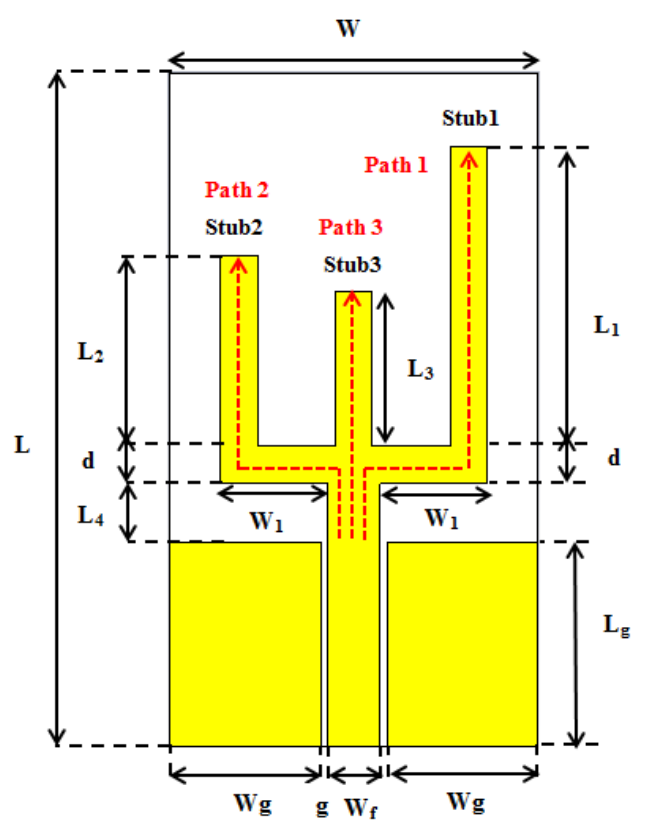

(a)

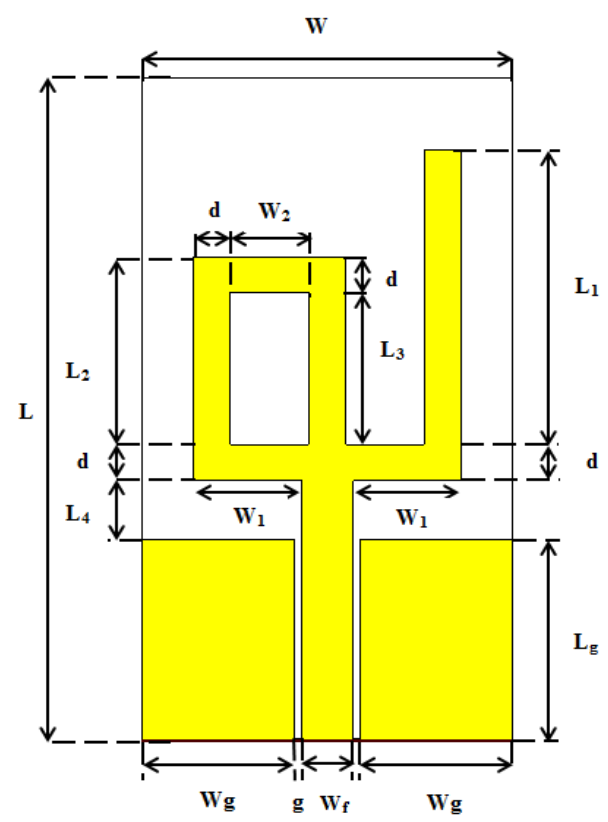

(b)

Fig. 1. (a) Geometry of the initial antenna, (b) Geometry of the proposed antenna.

The radiating element is composed by three Stubs: inverted L-shaped Stub1 with $\mathrm{L}_{1}=16.5 \mathrm{~mm}$, Lshaped Stub2 with $L_{2}=10.5 \mathrm{~mm}$ and a rectangle Stub3 with $\mathrm{L}_{3}=8.5 \mathrm{~mm}$, as shown in Fig. 1 (a). By adjusting the lengths $\left(\mathrm{L}_{1}, \mathrm{~L}_{2}\right.$ and $\left.\mathrm{L}_{3}\right)$ of these Stubs, three resonant frequencies can be generated and adjusted independently. The optimized geometrical parameters describing the proposed antenna are tabulated in Table I.

TABLE I. THE OPTIMIZED PROPOSED ANTENNA PARAMETERS

\begin{tabular}{cc}
\hline Parameters & Values $(\mathbf{m m})$ \\
\hline $\mathrm{W}$ & 20 \\
$\mathrm{~L}_{1}$ & 16.5 \\
$\mathrm{~L}_{3}$ & 8.5 \\
$\mathrm{~W}_{1}$ & 7.225 \\
$\mathrm{~L}_{\mathrm{g}}$ & 11.2 \\
$\mathrm{~d}$ & 2 \\
$\mathrm{~L}$ & 37 \\
$\mathrm{~L}_{2}$ & 10.5 \\
$\mathrm{~L}_{4}$ & 3.3 \\
$\mathrm{~W}_{\mathrm{g}}$ & 8.2 \\
$\mathrm{~W}_{\mathrm{f}}$ & 2.8 \\
$\mathrm{~W}_{2}$ & 5.625 \\
\hline
\end{tabular}

Fig. 2 shows the different shapes in the evolution of the proposed antenna and the simulated result of the reflection coefficient of the proposed antenna is presented in Fig. 3. The structure illustrated in Shape 1 of Fig. 2 is the basic CPW-fed planar antenna which consists by an inverted L-shaped Stub1 acting as the monopole. When an additional L-shaped Stub2 is embedded to the monopole of Shape 1 (Shape 2), a second resonant mode at $3.50 \mathrm{GHz}$ band is generated and two operating bandwidths are 
obtained. Afterwards, a rectangle Stub3 is added to the Shape 2 (Shape 3) and the triple-band structure is obtained: The first band from 2.519 to $2.673 \mathrm{GHz}(154 \mathrm{MHz})$ centered at $2.603 \mathrm{GHz}$, the second band from 3.058 to $4 \mathrm{GHz}(942 \mathrm{MHz})$ centered at $3.429 \mathrm{GHz}$ and the third band from 4.437 to $6.761 \mathrm{GHz}(2324 \mathrm{MHz})$ centered at $4.584 \mathrm{GHz}$.

Finally, we can observe that the assembled between Stub2 and Stub3 (Proposed antenna) can provide a wide band which cover all the WiMAX 3.5/5.5 GHz bands and the WLAN 5.2/5.8 GHz bands. From the simulated reflection coefficient of this proposed monopole antenna, a resonance at about $2.65 \mathrm{GHz}$ is seen for the first band and two resonance frequencies $3.50 \mathrm{GHz}$ and $5.956 \mathrm{GHz}$ are showed for the second broadband. Two operating bandwidths $\left(S_{11} \leq-10 \mathrm{~dB}\right)$ are achieved: The first band from 2.519 to $2.729 \mathrm{GHz}(210 \mathrm{MHz})$ and the second band from 3.093 to $6.684 \mathrm{GHz}$ (3591 $\mathrm{MHz})$.

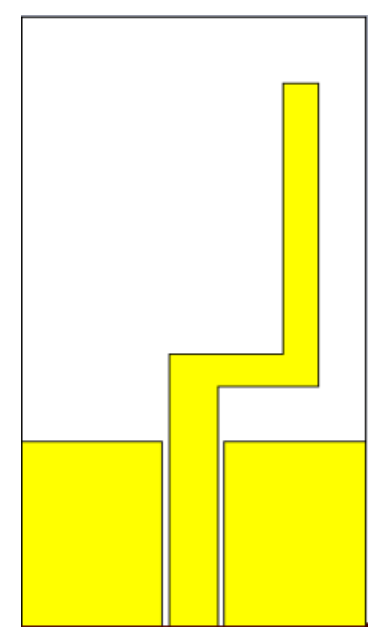

Shape 1

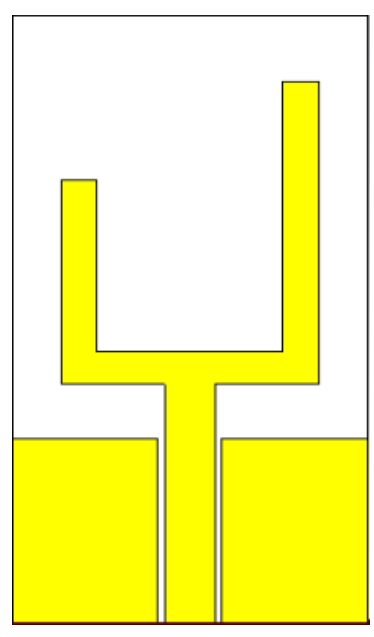

Shape 2

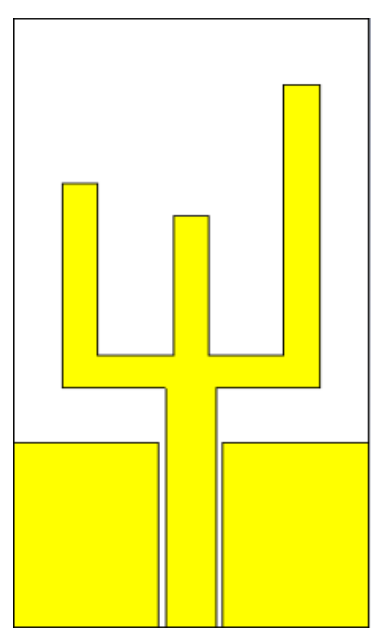

Shape 3

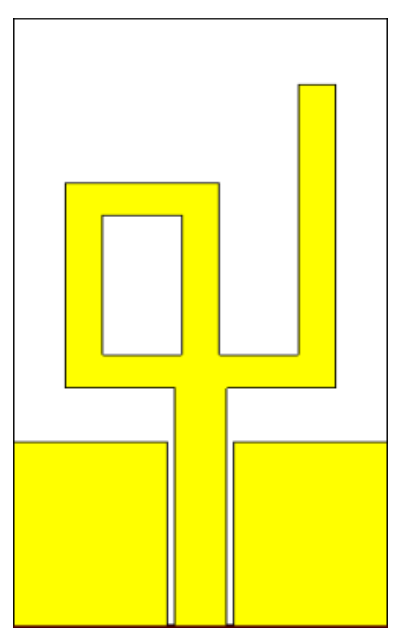

Proposed Antenna

Fig. 2. Evolution of the proposed CPW-fed monopole antenna.

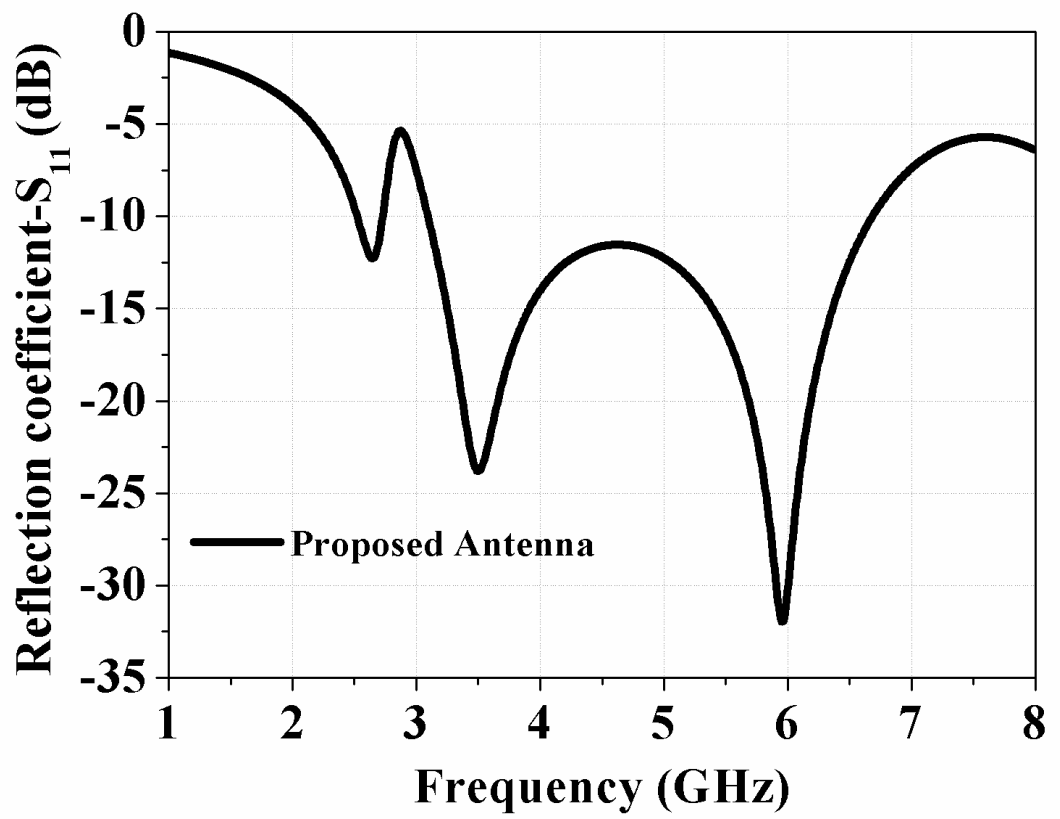

Fig. 3. Simulated result of the reflection coefficient against frequency for the proposed antenna. 
Table II shows a comprehensive comparison antenna size among our proposed antenna and other compact multi-band antennas. As for our proposed antenna with an excellent dual-band characteristic and a smaller size than those of the previously proposed dual-band antennas.

TABLE II. COMPARISONS OF ANTENNA SIZE AMONG PROPOSED ANTENNA AND OTHER COMPACT ANTENNAS

\begin{tabular}{|c|c|c|c|c|}
\hline Number & $\begin{array}{l}\text { Published } \\
\text { literature Reference }\end{array}$ & Size & $\begin{array}{c}\text { Operating frequency } \\
\text { band }\end{array}$ & $\frac{\text { Size }}{\text { proposed antenna }}(\%)$ \\
\hline 1 & Peng and Ruan [2] & $30 \times 40 \mathrm{~mm}^{2}$ & $\begin{array}{c}2.50-2.75 \mathrm{GHz} \text { and } 4.60- \\
6.05 \mathrm{GHz}\end{array}$ & 61.66 \\
\hline 2 & Peng and Ruan [4] & $28 \times 38 \mathrm{~mm}^{2}$ & $\begin{array}{c}2.25-2.65 \mathrm{GHz} \text { and } 4.99- \\
5.91 \mathrm{GHz}\end{array}$ & 69.54 \\
\hline 3 & Pan et al. [6] & $48 \times 58 \mathrm{~mm}^{2}$ & $\begin{array}{c}2.01-4.27 \mathrm{GHz} \text { and } 5.06- \\
6.79 \mathrm{GHz}\end{array}$ & 26.60 \\
\hline 4 & Chu and Ye [8] & $28 \times 33 \mathrm{~mm}^{2}$ & $\begin{array}{c}2.24-2.81 \mathrm{GHz} \text { and } 3.35- \\
6.51 \mathrm{GHz}\end{array}$ & 80.08 \\
\hline 5 & Karli and Ammor [19] & $60 \times 70 \mathrm{~mm}^{2}$ & $\begin{array}{c}2.72-2.76 \mathrm{GHz} \text { and } 6.62- \\
7.5 \mathrm{GHz}\end{array}$ & 17.61 \\
\hline 6 & Tsai [20] & $50 \times 50 \mathrm{~mm}^{2}$ & $\begin{array}{c}1.90-2.75 \mathrm{GHz} \text { and } 3.65- \\
6.75 \mathrm{GHz}\end{array}$ & 29.60 \\
\hline 7 & Xie et al [21] & $40 \times 40 \mathrm{~mm}^{2}$ & $\begin{array}{l}\text { 3.15-3.70 GHz and } 5.05- \\
5.97 \mathrm{GHz}\end{array}$ & 46.25 \\
\hline 8 & Sim et al. [22] & $30 \times 45 \mathrm{~mm}^{2}$ & $\begin{array}{c}2.140-2.750 \mathrm{GHz} \text { and } \\
5.05-6.16 \mathrm{GHz}\end{array}$ & 54.81 \\
\hline 9 & Wu et al. [23] & $75 \times 75 \mathrm{~mm}^{2}$ & $\begin{array}{c}2.410-2.785 \mathrm{GHz} \text { and } \\
4.575-6.355 \mathrm{GHz}\end{array}$ & 13.15 \\
\hline
\end{tabular}

\section{PARAMETRIC STUDY}

The parametric study is important for a design because it provides some understanding of the antenna characteristics to the antenna designer. Therefore, the effects of the design parameters for $\mathrm{L}_{1}$, $\mathrm{L}_{2}, \mathrm{~L}_{3},\left(\mathrm{~L}_{2}\right.$ and $\left.\mathrm{L}_{3}\right), \mathrm{W}_{1}$ and $\mathrm{L}_{\mathrm{g}}$ on the initial antenna and the proposed monopole antenna characteristics are investigated here. The study is based on the antennas structures shown in Fig. 1.

A. The inverted L-shaped Stub1 $\left(L_{1}\right)$

The effects of the length $L_{1}$ of the initial antenna are plotted in Fig. 4(a). This figure shows the simulated reflection coefficient when the length of $\mathrm{L}_{1}$ changes $\left(\mathrm{L}_{2}=10.5 \mathrm{~mm}\right.$ and $\left.\mathrm{L}_{3}=8.5 \mathrm{~mm}\right)$. By adjusting the length of $L_{1}$, the total length of Stub1 varies. It is seen that the increase in $L_{1}$ decreases the resonant frequency of the first band and vice versa. The resonant frequency of the third band is also affected.

Fig. 4(b) shows the variation of the reflection coefficient of the proposed antenna when the length of the first Stub $\mathrm{L}_{1}$ changed from $15.5 \mathrm{~mm}$ to $18.5 \mathrm{~mm}$. 


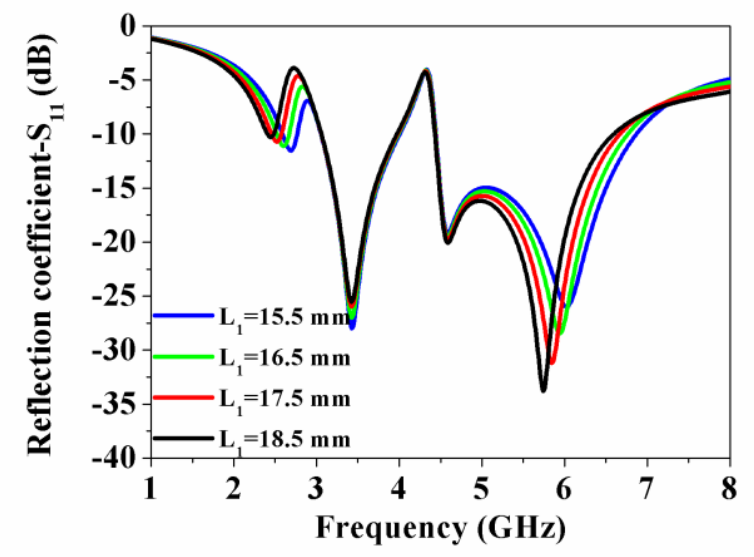

(a)

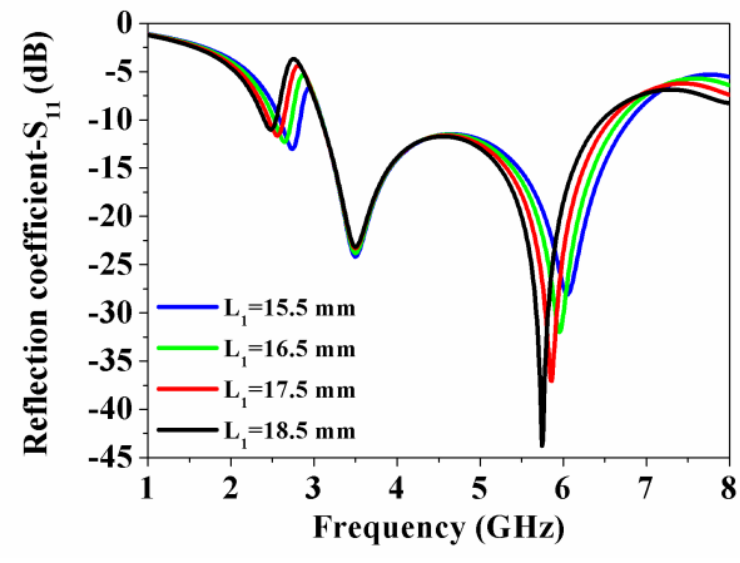

(b)

Fig. 4. Simulated reflection coefficients for different values of: (a) $L_{1}$ of the initial antenna and (b) $L_{1}$ of the proposed antenna.

\section{B. The L-shaped Stub2 $\left(L_{2}\right)$ of the initial antenna}

Fig. 5(a) shows the simulation of the reflection coefficient with variation of $\mathrm{L}_{2}\left(\mathrm{~L}_{1}=16.5 \mathrm{~mm}\right.$ and $\mathrm{L}_{3}=8.5 \mathrm{~mm}$ ) of the antenna presented in Fig. 1(a). By tuning the length of $\mathrm{L}_{2}$ from $9.5 \mathrm{~mm}$ to 12.5 $\mathrm{mm}$, it is clear that the raise in $\mathrm{L}_{2}$ decreases the resonant frequency of the second band. The resonant frequency of the first band is slightly affected.

\section{The rectangle Stub3 $\left(L_{3}\right)$ of the initial antenna}

Varying the length $\mathrm{L}_{3}$ of the initial antenna to be 7.5, 8.5, 9.5 and $10.5 \mathrm{~mm}$, it can be seen from Fig. 5(b) and Table III that with the increasing of length $\mathrm{L}_{3}$, the third resonant frequency shifts towards the lower frequency with an increase in the third band slightly, while the other resonant frequencies bands have not been changed.

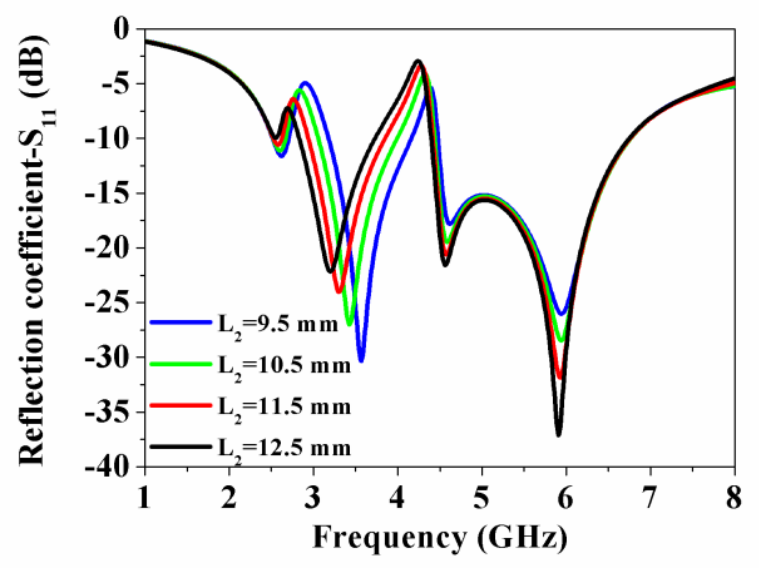

(a)

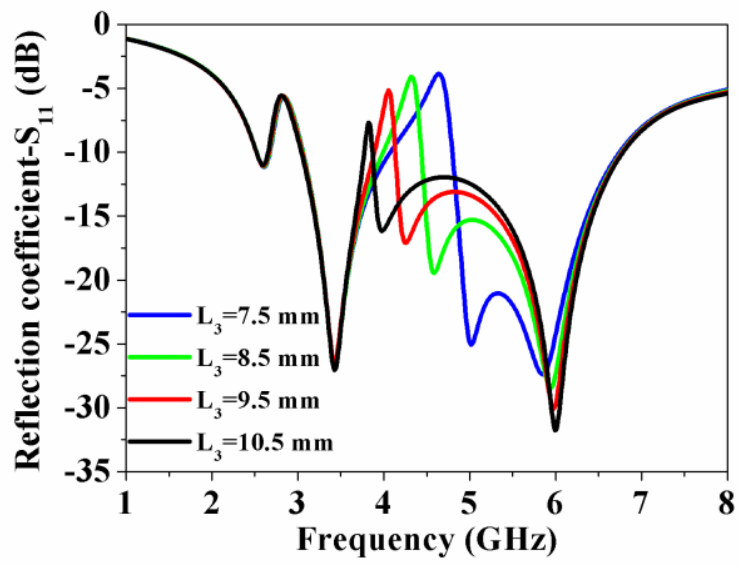

(b)

Fig. 5. Simulated reflection coefficients for different values of: (a) $\mathrm{L}_{2}$ of the initial antenna and (b) $\mathrm{L}_{3}$ of the initial antenna. 
TABLE III. THE VALUES OF BANDWIDTH OF THE THIRD BAND FOR DIFFERENT VALUES OF L S $_{3}$ OF THE INITIAL ANTENNA

\begin{tabular}{cc}
\hline Length $\mathbf{L}_{\mathbf{3}}(\mathbf{m m})$ & Third Band $(\mathbf{G H z})$ \\
\hline 7.5 & $4.794-6.754(1.940 \mathrm{GHz})$ \\
8.5 & $4.437-6.768(2.331 \mathrm{GHz})$ \\
9.5 & $4.129-6.775(2.646 \mathrm{GHz})$ \\
10.5 & $3.870-6.789(2.919 \mathrm{GHz})$ \\
\hline
\end{tabular}

\section{The simultaneous variation of $L_{2}$ and $L_{3}$ of the proposed antenna}

Fig. 6(a) shows the simulated reflection coefficient as a function of $L_{2}$, the length of Stub2 and $L_{3}$, the length of Stub3 of the proposed monopole antenna presented in Fig. 1(b). Small effects on the antenna's first and third resonant frequencies and large effects on the second resonant frequency are seen. The second band is shifted to lower frequencies with an increase in $L_{2}$ and the parameter $S_{11}$ of the third resonant frequency is ameliorated when raising the length $\mathrm{L}_{3}$.

\section{E. The width $W_{1}$ of the proposed antenna}

Fig. 6(b) shows the simulated reflection coefficient as a function of $\mathrm{W}_{1}$. It is seen from the plot that the 5-GHz operating band is strongly affected by the variations in $\mathrm{W}_{1}$, and the resonant frequency is shifted to lower frequencies when $\mathrm{W}_{1}$ is increased from $6.225 \mathrm{~mm}$ to $7.725 \mathrm{~mm}$ and the level of $\mathrm{S}_{11^{-}}$ parameter is enhanced from $-27.70 \mathrm{~dB}$ to $-58.57 \mathrm{~dB}$. Small effects on the antenna's first and middle bands are also seen from the plot.

\section{$F$. The effect of ground plane length $L_{g}$ of the proposed antenna}

The finite ground CPW feeding mechanism of the proposed antenna is the capability of impedance matching at the operating frequencies. For this, the effect of the ground plane length $\mathrm{L}_{\mathrm{g}}$ on the antenna characteristics has been illustrated. The effect of ground plane length $\mathrm{L}_{\mathrm{g}}$ on the impedance matching is investigated and the reflection coefficient for the proposed antenna is shown in Fig. 6(c). It is observed that higher value of $\mathrm{L}_{\mathrm{g}}$ gives a good impedance matching in the 5-GHz band.

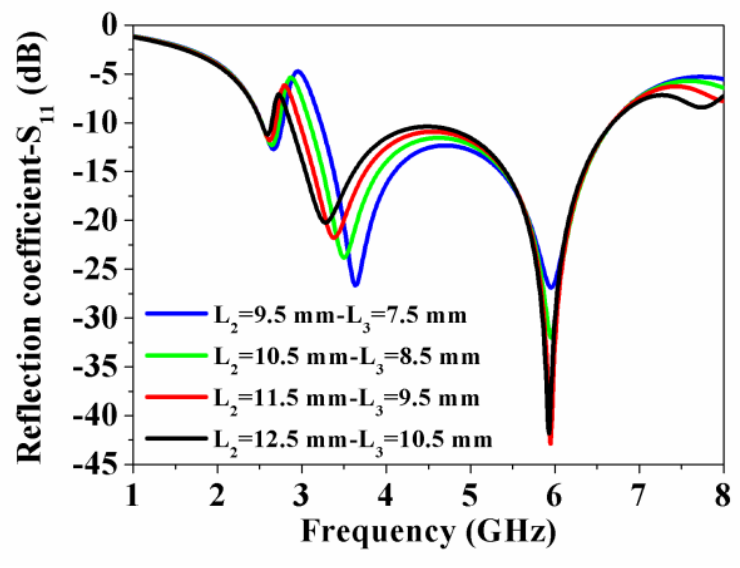

(a)

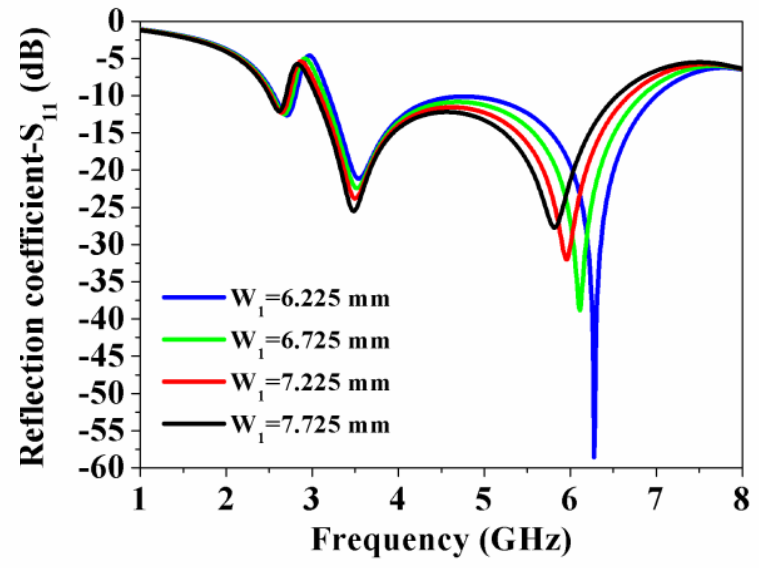

(b) 


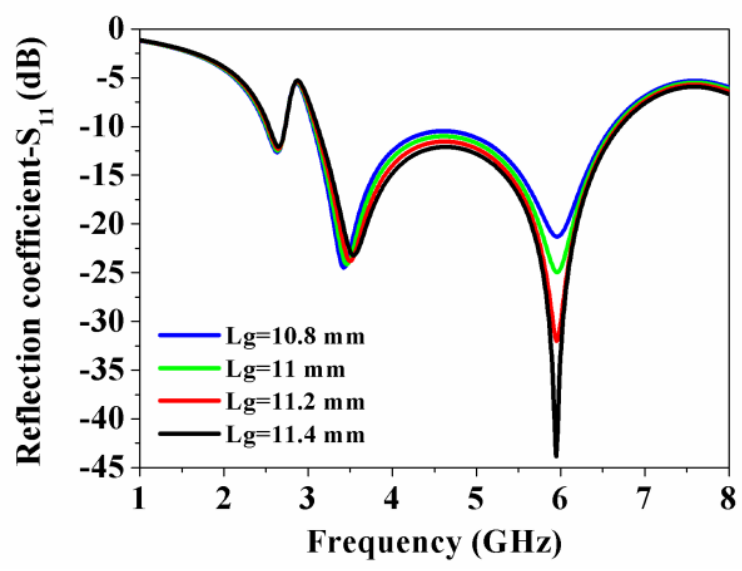

(c)

Fig. 6. Simulated reflection coefficients for different values of: (a) $\mathrm{L}_{2}$ and $\mathrm{L}_{3}$ of the proposed antenna (b) $\mathrm{W}_{1}$ of the proposed antenna and (c) $\mathrm{L}_{\mathrm{g}}$ of the proposed antenna.

\section{RESULTS AND DISCUSSION}

\section{A. Reflection coefficient results}

The dual-band planar monopole antenna is simulated using the CST Microwave Studio V13. A prototype structure of the proposed antenna has been constructed and experimentally studied. The SMA female connector is used for feeding with characteristic impedance of $50 \Omega$, as shown in Fig. 7 . The reflection coefficient is measured with Rohde and Schwarz ZVB 20 vector network analyzer, which its frequency range is, limited to $20 \mathrm{GHz}$. Fig. 8 shows the simulated and measured results of the reflection coefficient of the proposed antenna. The measured impedance bandwidths for $S_{11} \leq-10$ $\mathrm{dB}$ are about $110 \mathrm{MHz}\left(2.62\right.$ to $\left.2.73 \mathrm{GHz}, f_{\mathrm{r} 1}=2.69 \mathrm{GHz}\right)$ and $4280 \mathrm{MHz}\left(3.02\right.$ to $7.30 \mathrm{GHz}, f_{\mathrm{r} 2}=$ $4.28 \mathrm{GHz}$ and $f_{\mathrm{r} 3}=6.86 \mathrm{GHz}$ ), which makes it easy to cover the required bandwidths for WiMAX bands (3.40-3.69 GHz and 5.25-5.85 GHz), WLAN bands (5.15-5.35 GHz and 5.725-5.825 GHz) and a part of $2.60 \mathrm{GHz}$ band from 2.50 to $2.69 \mathrm{GHz}$. Seen from Fig. 8, the simulated $-10 \mathrm{~dB}$ impedance bandwidths for the first band is ranged from 2.519 to $2.729 \mathrm{GHz}(210 \mathrm{MHz})$ and for the second band is ranged from 3.093 to $6.684 \mathrm{GHz}$ (3591 MHz). We note a good agreement between the simulated and measured results with a good impedance matching in the operating bands. The small difference between the measured and simulated results is due to the effect of SMA connector soldering and fabrication tolerance.

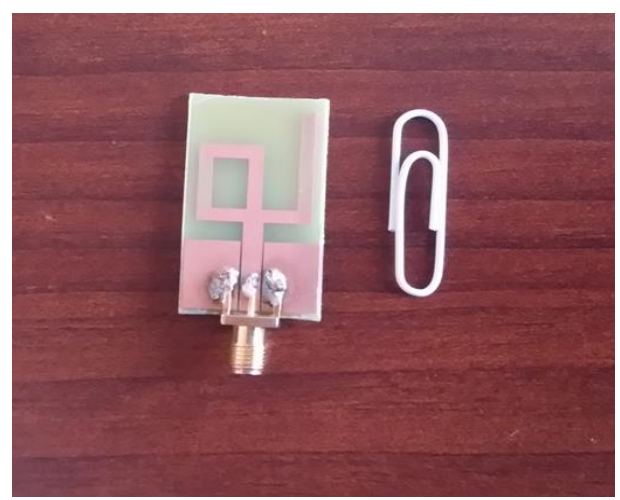

Fig. 7. Photograph of the fabricated antenna. 


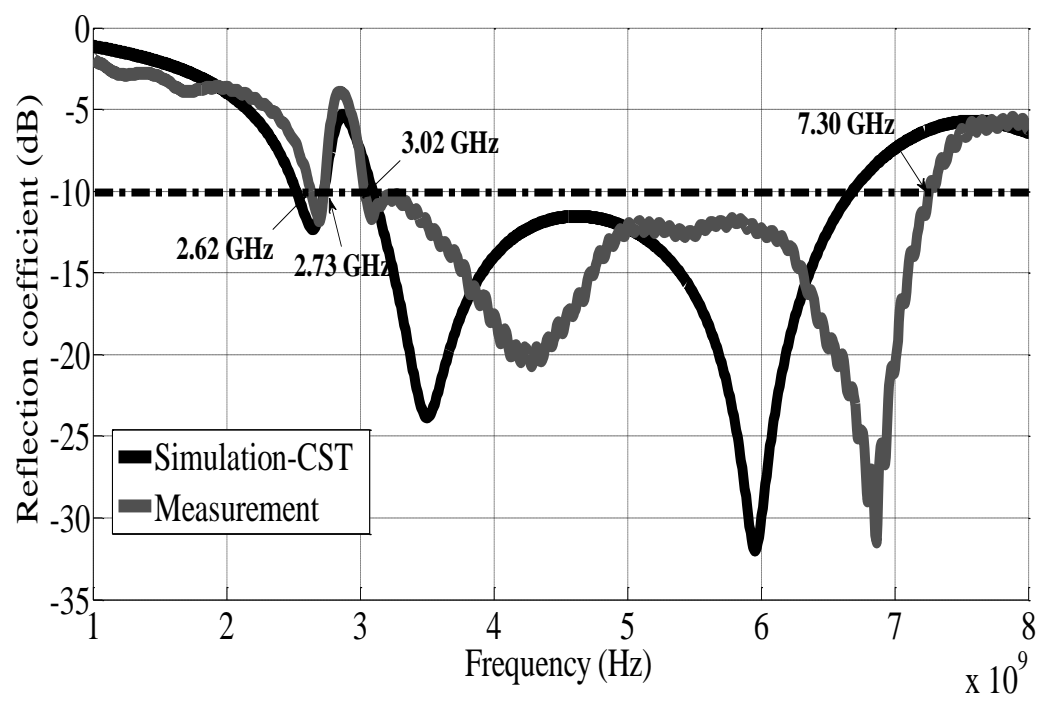

Fig. 8. The simulated and the measured reflection coefficient for the proposed antenna.

\section{B. Current distributions of the initial antenna}

From the simulated reflection coefficient characteristics of the initial antenna presented in Fig. 1(a), resonances can be observed at $f_{1}=2.603 \mathrm{GHz}, f_{2}=3.429 \mathrm{GHz}$ and $f_{3}=4.584 \mathrm{GHz}$. The probable current paths for the first, the second and the third resonance frequencies are similar to resonant Path 1, resonant Path 2 and resonant Path 3, respectively, as shown in Fig. 1(a) (red line).

In order to better understand the initial antenna behavior, the current distributions of the three-band antenna at frequencies of $2.603 \mathrm{GHz}, 3.429 \mathrm{GHz}$ and $4.584 \mathrm{GHz}$ are simulated and shown respectively in Figs. 9(a), (b) and (c). It can be evidently seen from Fig. 9 that the current distributions at the three resonant frequencies are different. Concerning the first resonant mode $\left(f_{1}=2.603 \mathrm{GHz}\right)$, a large surface of the current density is observed along the inverted L-shaped Stub1. Whereas for the second frequency band $\left(f_{2}=3.429 \mathrm{GHz}\right)$, the current distributions is mainly distributed along the Lshaped Stub2, on the other hand for the third resonant mode $\left(f_{3}=4.584 \mathrm{GHz}\right)$, the current distributions becomes more concentrated along the Stub3. Nevertheless, they also have a common characteristic that is a large current is concentrated along the feed line.

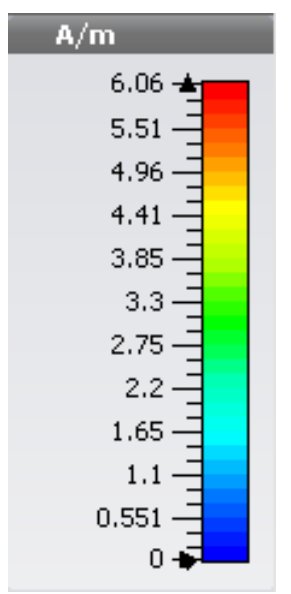

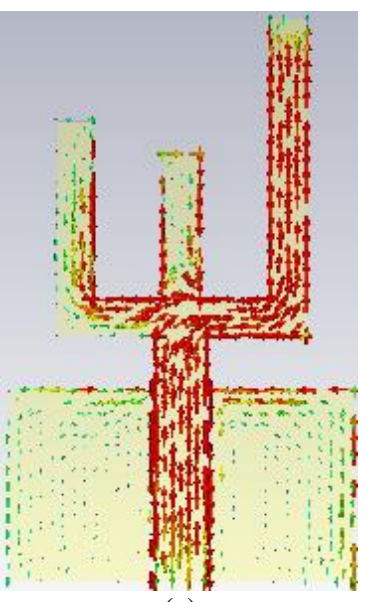

(a)

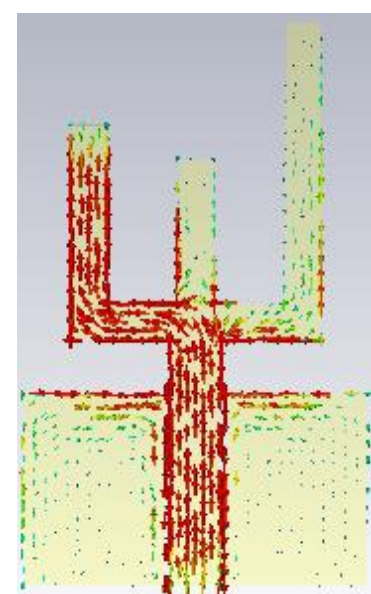

(b)

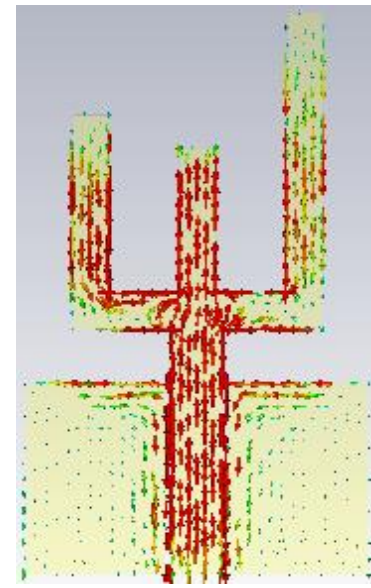

(c)

Fig. 9. Simulated current distribution of the initial antenna at frequencies (a) $2.603 \mathrm{GHz}$, (b) $3.429 \mathrm{GHz}$ and (c) $4.584 \mathrm{GHz}$. 


\section{Current distributions of the proposed antenna}

In order to further demonstrate the dual-band operation mechanism, the surface current distributions on the whole proposed antenna at different resonant frequencies are shown in Figs 10(a)-(c). It can be evidently seen that the current has different distributions along the optimized structure in different bands. Fig. 10(a) shows that the current distributions are forced to flow around the inverted L-shaped Stub1 and the rectangle Stub3. The variations on the length $\mathrm{L}_{1}$ affect the second resonant frequency of the wide band. Figs 10(b) and 10(c) show the current distributions at frequencies $3.50 \mathrm{GHz}$ and 4.60 GHz. The L-shaped Stub2 and the rectangle Stub3 contributed essentially to radiation at frequencies of $3.50 \mathrm{GHz}$ and $4.60 \mathrm{GHz}$, respectively. The resonant currents at frequencies of $3.50 \mathrm{GHz}$ and 4.60 $\mathrm{GHz}$ are distributed on both the Stub2 $\left(\mathrm{L}_{2}\right)$ and $\mathrm{Stub} 3\left(\mathrm{~L}_{3}\right)$.

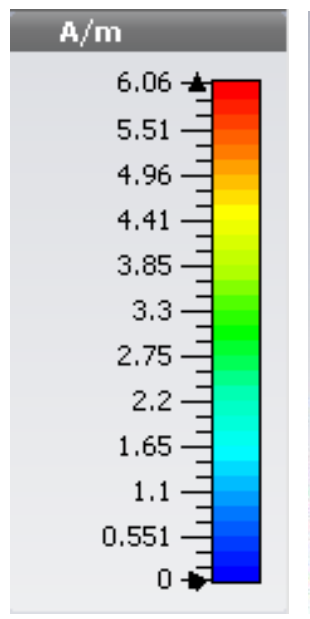

ig. 10. Simulated current distribution of the

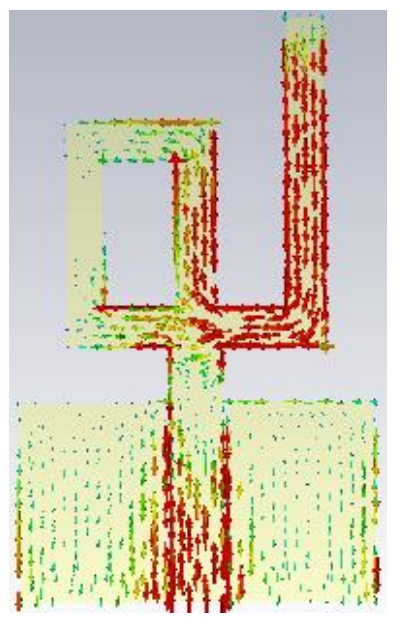

(a)

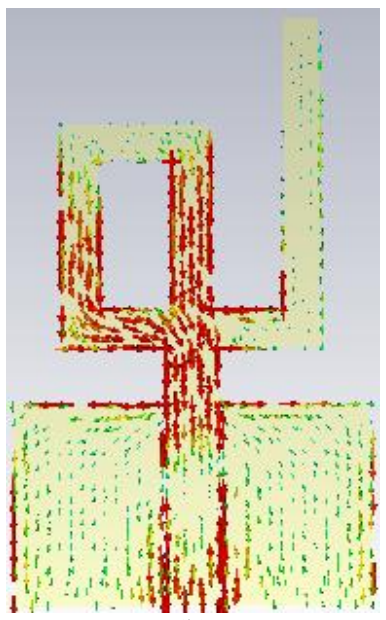

(b)

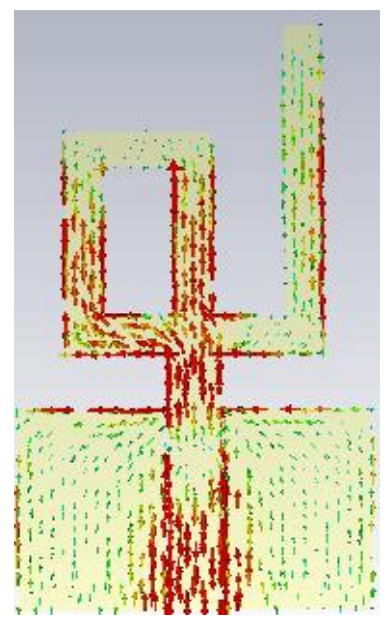

(c)

\section{Radiation patterns, gain and efficiency}

The Simulated E-plane (YOZ) and H-plane (XOZ) radiation patterns at 2.65, 3.50, 5.20 and 5.80 $\mathrm{GHz}$ are normalized and shown in Fig. 11. It is observed that the proposed antenna has almost an omni-directional radiation patterns in the H-plane and nearly bi-directional radiation patterns in the Eplane over the desired operating bands.

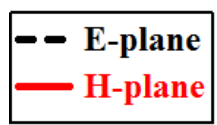

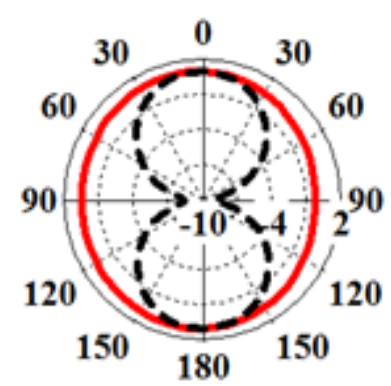

(a)

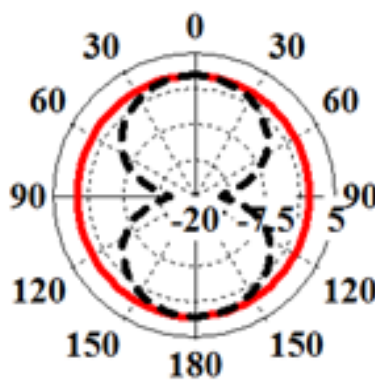

(b)

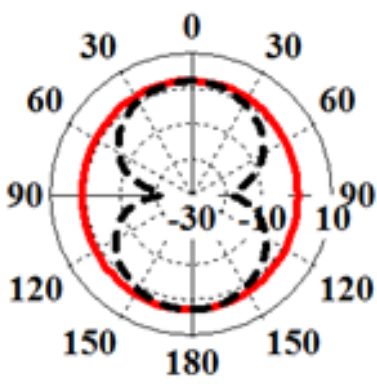

(c)

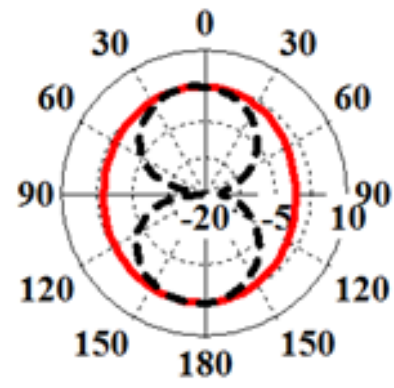

(d)

Fig. 11. Simulated 2D radiation patterns of the proposed antenna at frequencies (a) $2.65 \mathrm{GHz}$, (b) $3.50 \mathrm{GHz}$, (c) $5.20 \mathrm{GHz}$ and (d) $5.80 \mathrm{GHz}$. 
Fig. 12(a) and Fig. 12(b) show simulated peak gain and radiation efficiency across the operating bands. The maximum simulated peak antenna gains and radiation efficiencies are 1.45/1.55/3.31dBi and $81.1 / 77.5 / 75 \%$ at the first band and the second band, respectively.

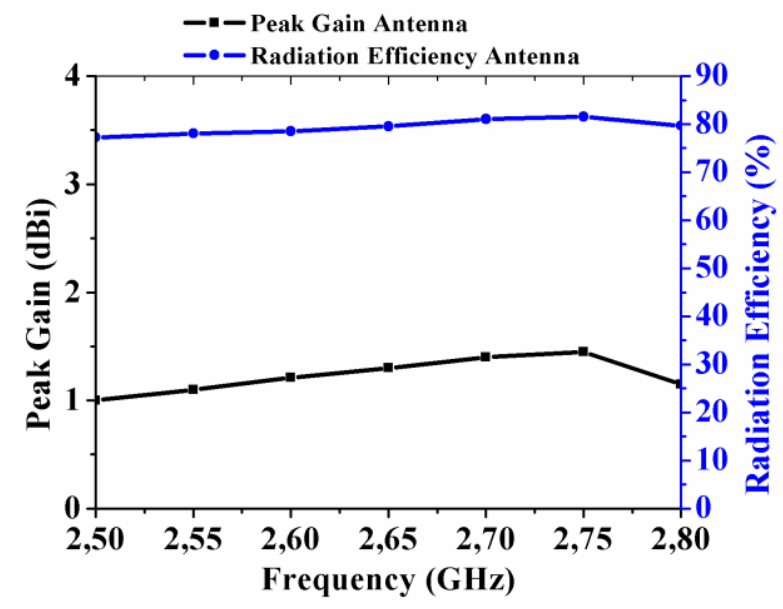

(a)

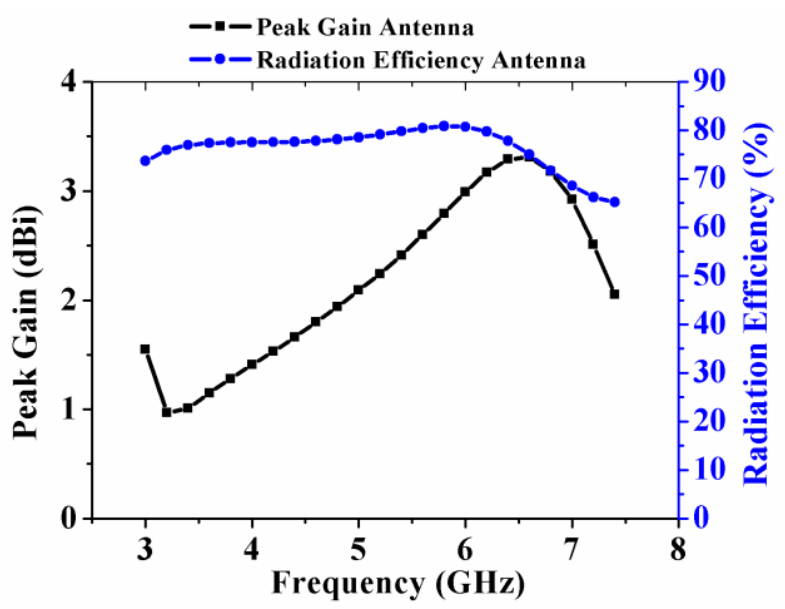

(b)

Fig. 12. Simulated peak gain and radiation efficiency across operating frequencies for proposed monopole antenna (a) first band, (b) second band.

\section{CONCLUSION}

A small monopole antenna for dual-band operations has been presented. The proposed monopole antenna has a simple planar structure and is easy to be printed on FR4 substrate with small size of 20 $\times 37 \mathrm{~mm}^{2}$. The initial antenna consists by three Stubs: inverted L-shaped Stub1, L-shaped Stub2 and rectangle Stub3. This configuration can generate three bands centered at about $2.603 \mathrm{GHz}, 3.429 \mathrm{GHz}$ and $4.584 \mathrm{GHz}$. The three resonant frequencies can be tuned individually by adjusting the length of the three Stubs. Thus, by combining between Stub2 and Stub3 (proposed antenna), two operating bands can be obtained with a wide second band which covers all the WiMAX bands $3.5 / 5.5 \mathrm{GHz}$ and WLAN bands 5.2/5.8 GHz. Both the simulated and measured results show that the demonstrated antenna can successfully achieved two operating bands. The measured $-10 \mathrm{~dB}$ reflection coefficient bandwidths cover 2.62-2.73 GHz (110 MHz) and 3.02-7.30 GHz (4280 MHz) bands, which satisfied the frequency requirements of WiMAX, WLAN and a part of the $2.6 \mathrm{GHz}$ band from 2.50 to 2.69 GHz. In addition, the proposed antenna provides good radiation patterns in the working bands, which makes it suitable for integrating into portable devices. This CPW-fed planar monopole antenna is a good candidate for wireless communication systems.

\section{ACKNOWLEDGMENT}

This work was supported by the National Center for Scientific and Technical Research (CNRST). The authors would like to thank Professor Naima Amar Touhami from Faculty of Sciences of Tetouan for its beneficial and professional help in the realization of the proposed antenna. 


\section{REFERENCES}

[1] S. Jo, H. Choi, B. Shin, S. Oh, and J. Lee, "A CPW-Fed Rectangular Ring Monopole Antenna for WLAN Applications,” International Journal of Antennas and Propagation, vol. 2014, Article ID 951968, 2014.

[2] L. Peng, and C.-Li Ruan, "A Microstrip Fed Patch Antenna with Two Parasitic Invert L Stubs for Dual-Band WLAN Applications,” Wirel. Pers. Commun, vol. 57, no. 4, pp. 727-734, 2011.

[3] L. Zhang, Y.-C. Jiao, G. Zhao, Y. Song, and F.-S. Zhang, "Broadband Dual-Band CPW-Fed Closed Rectangular Ring Monopole Antenna with a Vertical Strip for WLAN Operation," Microwave and Optical Technology Letters, vol. 50, no. 7, pp. 1929-1931, 2008.

[4] L. Peng, and C.-L. Ruan, "A Microstrip Fed Monopole Patch Antenna with three Stubs for Dual-band WLAN Applications," J. of Electromagn. Waves and Appl, vol. 21, no. 15, pp. 2359-2369, 2007.

[5] C.-Y. Huang, and E.-Z. Yu, “A Slot-Monopole Antenna for Dual-Band WLAN Applications," IEEE Antennas Wirel. Propag. Lett, vol. 10, pp. 500-502, 2011.

[6] C.-Y. Pan, T.-S. Horng, W.-S. Chen, and C.-H. Huang, "Dual Wideband Printed Monopole Antenna for WLAN/WiMAX Applications,” IEEE Antennas Wirel. Propag. Lett, vol. 6, pp. 149-151, 2007.

[7] J. Il Kim, and Y. Jee, "Design of Ultra wideband Coplanar Waveguide-Fed LI-Shape Planar Monopole Antennas," IEEE Antennas Wirel. Propag. Lett, vol. 6, pp. 383-387, 2007.

[8] Q.-X. Chu, and L.-H. Ye, "Design of Compact Dual-Wideband Antenna with Assembled Monopoles," IEEE Trans. Antennas Propag, vol. 58, no. 12, pp. 4063-4066, Dec. 2010.

[9] S. T. Fan, Y. Z. Yin, W. Hu, K. Song, and B. Li, “ Novel CPW-Fed Printed Monopole Antenna with an n-Shaped Slot for Dual-Band Operations," Microwave and Optical Technology Letters, vol. 54, no. 1, pp. 240-242, 2012.

[10] C.-M. Wu, J.-W. Syu, and W.-C. Liu, "Dual-Band Slotted Patch Antenna with Defective Ground for WLAN/WiMAX Applications, ” Progress In Electromagnetics Research Letters, vol. 53, pp. 1-6, 2015.

[11] W. C. Liu, and W. R. Chen, "CPW-fed compact meandered patch antenna for dual-band operation," Electronics Letters, vol. 40, no. 18, pp. 1094-1095, 2004.

[12] H.-D. Chen, and H.-T. Chen, "A CPW-Fed Dual-Frequency Monopole Antenna," IEEE Trans. Antennas Propag, vol. 52, no. 4, pp. 978-982, 2004.

[13] W. Hu, Y.-Z. Yin, P. Fei, and X. Yang, "Compact Triband Square-Slot Antenna with Symmetrical L-Strips for WLAN/WiMAX Applications," IEEE Antennas Wirel. Propag. Lett, vol. 10, pp. 462-465, 2011.

[14] A. Boutejdar, A. A. Ibrahim, and E. P. Burte, "A Compact Multiple Band-Notched Planer Antenna with Enhanced Bandwidth Using Parasitic Strip Lumped Capacitors and DGS-Technique," TELKOMNIKA Indonesian Journal of Electrical Engineering, vol. 13, no. 2, pp. 203-208, 2015.

[15] A. Boutejdar, A. A. Ibrahim, and E. P. Burte, "Novel Microstrip Antenna Aims at UWB Applications," Microwaves \& $R F$, vol. 7, no. 7, pp. 8-14, 2015.

[16] A. A. Ibrahim, M. A. Abdalla, and A. Boutejdar, "Resonator Switching Techniques for Notched UWB Antenna in Wireless Applications," IET Microwaves, Antennas \& Propagation, vol. 9, no. 13, pp. 1468-1477, 2015.

[17] A.A. Ibrahim, M.A. Abdalla, and A. Boutejdar, "A Printed Compact Band Notched Antenna Using Octagonal Radiating Patch and Meander Slot Technique for UWB Applications," Progress In Electromagnetics Research M , vol. 54, pp. 153-162, 2017.

[18] A. Boutejdar, and W. Abd Ellatif, "A novel compact UWB monopole antenna with enhanced bandwidth using triangular defected microstrip structure and stepped cut technique," Microwave and Optical Technology Letters, vol. 58, no. 6, pp. 1514-1519, 2016.

[19] R. Karli, and H. Ammor, "Rectangular patch antenna for dual-band RFID and WLAN applications," Wirel. Pers. Commun, vol. 83, no. 2, pp. 995-1007, 2015.

[20] Lin C. Tsai, "Design of Triple-Band T-U-Shaped CPW-Fed Slot Antennas," Microwave and Optical Technology Letters, vol. 56, no. 4, pp. 844-848, 2014. 
[21] J.-J. Xie, X.-S. Ren, Y.-Z. Yin, and S.-L. Zuo, "Rhombic Slot Antenna Design with a Pair of Straight Strips and Two n-Shaped Slots for WLAN/WiMAX Applications," Microwave and Optical Technology Letters, vol. 54, no. 6, pp. 1466-1469, 2012.

[22] C.-Y.-Desmond Sim, Y.-W. Hsu, and C.-H. Chao, "Dual Broadband Slot Antenna Design for WLAN Applications," Microwave and Optical Technology Letters, vol. 56, no. 4, pp. 983-988, 2014.

[23] J.-W. Wu, H.-M. Hsiao, J.-H. Lu, and S.-H. Chang, "Dual broadband design of rectangular slot antenna for 2.4 and $5 \mathrm{GHz}$ wireless communication," Electronics Letters, vol. 40, no. 23, pp. 1461-1463, 2004. 